\title{
Amor mundi e espírito revolucionário: Hannah Arendt entre política e ética
}

\author{
Amor mundi and the revolutionary spirit: Hannah Arendt between \\ politics and ethics
}

Igor Vinícius Basílio Nunes

ivbnunes@hotmail.com

(Universidade de Campinas, São Paulo, Brasil)

\begin{abstract}
Resumo: Este artigo delineia alguns contornos interpretativos da expressão "amor mundi" nas formulações teóricas de Hannah Arendt e, principalmente, em contato direto com a obra Sobre a Revolução. 0 texto acompanha, portanto, as definições possíveis desses três termos - "amor", "mundo" e "revolução" - na tentativa não só de evidenciar significados ao conhecido emblema político arendtiano, mas também de defender certa conciliação entre a "responsabilidade pelo mundo político" legado aos homens e o "cuidado com o eu moral". Em poucos termos, a proposta é sugerir uma via de interpretação não apenas política da expressão amor mundi, mas, também, ética e de espírito revolucionário.
\end{abstract}

Palavras-chave: amor; política; mundo; ética; revolução.

\begin{abstract}
This article outlines some interpretive contours of the expression "amor mundi" in Hannah Arendt's theoretical formulations, especially in contact with the work On Revolution. The text follows, therefore, some possible definitions of these three terms - "love", "world" and "revolution" - in an attempt not only to clarify the meanings of Arendt's political emblem, but also to defend the right balance between "responsibility for the political world" legacy to men and the "care of the moral self ". In a few words, the proposal is to suggest a way of interpretation not only political about amor mundi, but also in respect with ethics and the revolutionary spirit.
\end{abstract}

Keywords: love; politics; world; ethics; revolution.

Uma das frentes subversivas de Hannah Arendt em oposição à tradição do pensamento político ocidental, por assim dizer, se dá pela maneira como a pensadora interpreta a linguagem teológica e de como faz questão de não negligenciar, em suas reflexões teóricas, os acontecimentos históricos de cunho religioso - sobretudo cristão. "É da natureza de nossa tradição (...) ser altamente seletiva e excluir da conceitualização articulada grande variedade de experiências políticas autênticas" (Arendt, 2010, pp.297-8). Em algumas de suas obras e textos editados, como em Sobre a Revolução, a seriedade com que Arendt se refere a passagens da escritura bíblica pode incomodar alguns de seus leitores em virtude do suposto estatuto ético-político que a autora entrevê em certos aspectos dos ensinamentos de Jesus de Nazaré e na 
comunidade religiosa de seus seguidores ${ }^{1}$. Contudo, como em grande parte de seus estudos, as interações e, principalmente, as apropriações de Arendt em relação a suas referências bibliográficas não são pacíficas e nem passivas. Pelo contrário, o contato da pensadora com materiais alheios, que lhe serviam para intertextos, é usualmente marcado pelo desarranjo (que não é confusão) e pela posse (que não é necessariamente de direito). Em outros termos: as leituras de Arendt são vivas, críticas e, mais do que meramente interpretativas, são antropofágicas, no sentido de reter o que bem entender daquilo que deglute. Já diria Jaspers, em uma carta a Heidegger em 20 de junho de 1929, que a Senhorita Arendt recém-doutorara com um trabalho que assumia “citações historicamente arriscadas” (Biemel; Saner, 1990, p.99). Talvez por isso também o diagnóstico final do orientador tenha sido: “ela, simplesmente, não reuniu tudo o que Agostinho disse sobre o amor (...) Alguns erros surgem nas citações (...) O método exerce alguma violência sobre o texto (...) Não merece, infelizmente, a mais alta menção" (apud Kristeva, 2002, p.41). Bem ou mal, em todo caso, pelo menos uma característica da aluna permaneceu posteriormente nas obras da professora/pensadora renomada: que seria a capacidade de refletir, ao mesmo tempo, com e contra alguns autores - Agostinho, entre eles, também Kant, Platão, Marx e outros - , não poucas vezes se utilizando de argumentos internos às obras destes para criticá-los, colocando determinado pensador contra ele mesmo. Desse modo, com os assuntos religiosos a atitude de Arendt não poderia ser diferente. Ainda que esses temas representassem parte intensa de sua formação e lhe acompanhassem enquanto registro de fontes às quais lançar mão sem preconceitos, sua leitura não deixava de ser, de certa forma, profana. É como se a chave de compreensão do método de abordagem arendtiano desses assuntos religiosos, como um todo, estivesse resguardada na Introdução de sua tese sobre o conceito de amor em Agostinho, no momento em que Arendt justifica o segundo ponto de dificuldades que limitariam a sua pesquisa de doutoramento. Naquele contexto, afirma ela: "as nossas análises manter-se-ão em grande parte alheias à submissão do ponto de vista do dogma (...) à autoridade das Escrituras e da Igreja, porque por princípio são livres em relação ao dogma na sua essência e no seu sentido" (Arendt, 1997, p.9). Isso valeria, crê-se aqui, até mesmo para interpretar vários aspectos de sua obra de maturidade.

Essa breve introdução tem uma explicação bem simples: a de legitimar o

\footnotetext{
1 Ao comentar a respeito do vínculo entre a violência e a capacidade humana de dar início a novidades no mundo, isto é, ao se referir à instituição criminosa de todas as fraternidades e fundações humanas, a título de exemplo, em Sobre A Revolução, Arendt confere aplicabilidade política à narrativa bíblica e metafórica de Caim e Abel e, nesse contexto, filia aos negócios dos assuntos humanos o autoevidente ato de fala fundador "no início há um crime" em comparação com a força religiosa da frase de São João, "No princípio era o Verbo", sobre o criador dos céus e da terra. Além desse exemplo, em várias passagens de suas obras, de $A$ Condição Humana até ao póstumo publicado livro $A$ Vida do Espírito, pode-se afirmar que uma das frases mais utilizadas por Arendt na tentativa de enfatizar a importância da pluralidade no espaço público é "Deus criou os homens", e não o homem no singular.
} 
que este texto pretende. A saber: rastrear alguns esparsos e poucos sistematizados momentos em que Arendt trata direta ou indiretamente da expressão "amor", ponderando de antemão que são momentos nos quais as referências ao léxico religioso permanecem, de uma forma ou de outra, pelo menos como denominador comum das diversas discussões apresentadas. Especificamente, são quatro momentos pontuais abordados aqui e, vale ressaltar, retirados de preocupações temporais distintas e não necessariamente convergentes nas reflexões arendtianas, embora a tese sobre Agostinho não figure aqui entre os momentos selecionados. Tendo isso em conta, dois objetivos são centrais para este artigo a) perceber como o termo "amor" aparece em cada um desses momentos e relacioná-lo aos conceitos de mundo e de revolução; para, assim, tentar constatar o que significa o "amor mundi" em Arendt e como este se relaciona ao denominado "espírito revolucionário"; e b) sugerir uma via de interpretação não só política dessas expressões, mas, de maneira concomitante, aproximá-las ao pensamento ético da autora.

O primeiro ponto em apreciação, portanto, se encontra em A Condição Humana - obra que, como se sabe, teve como seu título provisório justamente o binome "Amor Mundi". Em duas passagens específicas desse livro, Arendt afirma a irrelevância do amor ao âmbito público, ao âmbito das aparências. Não que o amor seja irrelevante por si mesmo, mas ele simplesmente não é capaz de tolerar a luz implacável da cena pública e nem de suportar de modo digno a constante visibilidade perante a presença dos outros, pois ao ser exposto continuamente suscita desconfiança em relação à genuinidade do próprio sentimento. Assim como é impossível, para nós, ter acesso à intensidade da dor física que uma outra pessoa sente; também não há como conhecer e nem confiar plenamente no sentimento alheio, que tem no caso do amor um exemplo extremo. Em tais casos, o acesso a esses sentimentos é intrinsecamente privado. Devido a isso, na seção que explica o que seria o "domínio público" e o que seria o "comum” em sua reestruturação fenomenológica da vita activa, Arendt considera que algumas forças internas prementemente individuais - como a vida do espírito, as paixões do coração e os deleites dos sentidos - não são próprias a compor a realidade do mundo aparente. Ser algo automaticamente privado não significa ser algo rebaixado a um âmbito inferior ao público; significa apenas que cada atividade assinala sua melhor localização conveniente, ou seja, que há coisas que devem ser ocultadas e outras coisas que devem ser expostas para receber existência adequada. Dessa forma, diz Arendt: “O amor (...) em contraposição à amizade, morre ou, antes, se extingue assim que é trazido a público. Dada a sua inerente não mundanidade, o amor só pode ser falsificado e pervertido quando utilizado para fins políticos, como a transformação ou a salvação do mundo" (Arendt, 2010, p.63, grifos meus). Páginas adiante, ainda na obra $A$ Condição Humana, quando discute a respeito da redenção das vicissitudes ocasionadas pela irreversibilidade das ações humanas, isto 
é, quando discute sobre a envergadura política do perdão, característica que teria sido descoberta pelo Nazareno, Arendt volta à questão do amor, uma vez que perdoar e amar são indissociáveis na doutrina cristã. Diz ela: "Por natureza, o amor é não mundano, e é por essa razão, mais que por sua raridade, que é não apenas apolítico, mas antipolítico, talvez a mais poderosa das forças humanas antipolíticas" (idem, p.302). Ora, nesses dois contextos, a partir de diferentes justificativas, subjaz a mesma argumentação em Arendt que parte da seguinte premissa: o amor não suporta barreiras e distâncias, ele abole todo espaço-entre existente, segundo a pensadora, em qualquer constituição política organizada humanamente. Daí vem o aspecto antipolítico e não mundano do amor, pois é um sentimento que elimina todo tipo de espaço criado entre aquele que ama e aquilo que é amado; politicamente, isso quer dizer que, por seu caráter passional, o amor destrói aquilo que, ao mesmo tempo, nos une e nos separa uns aos outros. Nesse sentido, o amor definitivamente não é um bom critério para ações políticas, é fonte equivocada para guiar anseios revolucionários e não deve fazer parte argumentativa ou persuasiva no diálogo político, até porque a pluralidade teria de ser sacrificada em nome da experiência de um tipo de sentimento que é íntimo e que requer exclusividade, o que geraria um âmbito de intolerância e suspeita com aqueles que, por acaso, não compartilhassem de tal sentimento.

Trata-se, portanto, de uma encruzilhada análoga àquilo que tragou violentamente a maioria das revoluções, sobretudo a Francesa e a Russa, segundo Arendt, no sentido de se instaurar contextos marcados pelo "terrorismo da virtude" e pela punição de supostos vícios - como a hipocrisia - que não são de modo algum bem definidos e objetivamente apontáveis publicamente. Na leitura de Arendt, quando Robespierre, influenciado por Rousseau, vinculou a força virtuosa dos revolucionários franceses a um sentimento de piedade para com o povo (le peuple, os desgraçados, os sofredores, os menos abastados), perdia-se então a capacidade de representar o povo em uma causa comum em prol de um distanciamento entre representantes (os piedosos) e representados (os que merecem caridade). Mais do que isso, inauguravase uma constante suspeita por parte daqueles que se sentem piedosos em relação àqueles que, por acaso, não se sentem compadecidos com o povo. "O coração humano é, sem dúvida, um local de sombras que nenhum olhar humano pode devassar (...) fez com que Robespierre e seus seguidores, depois de igualarem a virtude às qualidades do coração, vissem intrigas e calúnias, traições e hipocrisias por todas as partes" (Arendt, 2011, p.136)2. Para Arendt, essa fatídica faceta da desconfiança não estava presente na Revolução Americana, pois os revolucionários americanos não tomaram

2 Há, nesse argumento, um sentido de comprovação do "caráter apolítico e antipolítico" do amor comentado em A Condição Humana, pois o coração humano, que contém os sentimentos mais privados de cada indivíduo, também não se destina a aparecer à luz do público. 
o coração, de onde provém o sentimento do amor, como fonte da virtude política e nem como fonte do caráter moral daqueles que governam. Tais revolucionários se incluíam entre os oprimidos, uma vez que também eram destituídos de poder político por conta de um antigo regime, e, desse modo, legitimaram-se por se erguerem contra a tirania e a opressão sem precisarem recorrer ao sentimento de solidariedade face à pobreza e à contínua exploração dos povos. "Se se tornaram porta-vozes do povo, não foi no sentido de que fizeram algo pelo povo, fosse por amor ou por desejo de obter poder sobre ele; falaram e agiram como seus representantes numa causa comum" (idem, p.110, grifo meu). Seria, assim, diante do exposto no primeiro movimento deste texto, o amor mundi contraditório por definição e impróprio para se adequar ao denominado "espírito revolucionário"?

Antes de tentar responder, cabe levantar mais alguns problemas e deixar a questão um tanto solta no ar. No último parágrafo da parte sobre o poder de perdoar em A Condição Humana, Arendt defende, contra a concepção cristã, que para perdoar não é preciso amar. Afinal, para ela, o perdão possui um papel político por ser, justamente, uma espécie de ação, ou melhor, um reinício em resposta a um determinado ato anterior que a provocou, mas trata-se de um reinício que não reage simplesmente, pois não está presa a este ato único. Perdoar é agir novamente, é tentar desfazer o que já foi feito, é libertar tanto o credor quanto o devedor de consequências que poderiam ser intermináveis, mas não teria uma força política se estivesse necessariamente vinculado ao amor - este entendido como força de grandeza antipolítica. Desse modo, afirma Arendt: “o que o amor é em sua esfera própria e estritamente delimitada, o respeito é no domínio mais amplo dos assuntos humanos. Como a philia politiké aristotélica, o respeito é uma espécie de amizade sem intimidade ou proximidade; é uma consideração pela pessoa desde a distância que o espaço do mundo coloca entre nós" (Arendt, 2010, p.303). Com isso a autora quer dizer, apenas, que o respeito, e não o amor, é o bastante para que possamos perdoar uns aos outros. Em todo caso, a questão do "respeito" abre espaço para o segundo momento de considerações aqui pretendidas.

Em uma carta de resposta às críticas dispensadas pelo teólogo judeu Gerschom Scholem ao seu livro Eichmann em Jerusalém, correspondência na qual Arendt rebate a acusação de ter "poucos traços de amor ao povo judeu”, a pensadora escreve que Scholem estava absolutamente correto em seu diagnóstico. Por duas razões principais: primeiro porque o amor a coletividades nunca a tinha comovido; e, segundo, porque seria suspeito ela, enquanto 'judia', declarar amor aos judeus. "De fato, eu amo 'apenas' os meus amigos e o único tipo de amor que conheço e no qual acredito é o amor pelas pessoas (...) Em segundo lugar, não posso amar a mim mesma nem nada que eu saiba ser parte e parcela de minha própria pessoa" (Arendt, 1978, pp.246-7). Arendt reitera essa sua posição em uma entrevista concedida a uma emissora de TV 
alemã, em 1964, ao dizer que acredita ser politicamente estéril fundamentar uma organização mundana entre homens pelo emblema do amor ${ }^{3}$. Pelo exposto nestes dois momentos em que Arendt relaciona os conceitos de amor e de mundo, ora em um testemunho e ora em sua principal obra de teor político, é interessante que ela insista na expressão "amor mundi" sem se dar ao trabalho de esclarecer precisamente o que compreende com isso. Por se tratar de Arendt, presume-se que a escolha conceitual não é mera trivialidade. Torna-se, então, instigante que a autora insista que a relação dos homens com o mundo tenha de ser pautada pelo "amor". Por que não "amizade mundi" ou "respeito mundi", já que ela confere papel político e mundanidade a tais sentimentos? Por certo, o que Arendt entende por "amor", nesse conceito, não pode se confundir com uma noção romantizada entre duas pessoas ou com qualquer sorte de sentimentalismo que nos remeta somente a nós mesmos ou que misture todos os homens numa indistinção patriótica cega.

O amor mundi simboliza uma disposição em partilhar com os outros, de maneira discursiva e ativa, das coisas e fatos mundanos. Mais do que tomar o mundo como um objeto, significa se responsabilizar por ele sem nunca perder o vínculo de pertencimento que une os homens ao mundo. Em suma, significa “cuidado": cuidado com aquilo que deve permanecer para além de nós mesmos, cuidado que se baseia pela salvaguarda em conjunto da pluralidade, do poder e da liberdade humanas. Com isso em vista, pode-se dizer que só existe revolução, nos termos de Arendt, se há homens disponíveis para a ação sob o signo do cuidado com o mundo. Fundar a liberdade por meio da constituição de um novo corpo político que sustenta e é sustentado pelo poder, "o único atributo humano que se aplica exclusivamente ao entremeio mundano onde os homens se relacionam entre si" (Arendt, 2011, p.228), como no caso americano, sem recorrência a nenhuma esfera além da política, é um sintoma de amor pelo mundo. E esse termo não poderia ser "amizade mundi" ou "respeito mundi", a propósito, porque, senão, seria algo que requereria reciprocidade. Não existe amizade sem que ambas as partes concordem com o sentimento; e até o mais egoísta dos homens reconheceria que deve respeito a quem o respeita, pelo menos no sentido de respeitar aquela parte do outro que o respeita. Como diz uma frase de Nietzsche, que Arendt cita em algumas ocasiões, "quem despreza a si próprio não deixa mesmo assim de se respeitar como desprezador" (Nietzsche, 2001, p.78). Enfim, com o amor é diferente. O mundo não precisa amar o homem de volta para que o cuidado político humano se sustente pelo e no amor mundi - podemos, sem equívocos, amar o que é inanimado.

Amizade e respeito são, entre vários, modos pelos quais o amor mundi se transfigura publicamente entre os homens. Dessa forma, não haveria contradição

3 "Admito, no entanto, que o povo judeu é um exemplo típico de formação popular acósmica que se mantém há milênios" (Arendt, 1993, p.138). 
em sustentar o amor como o signo de suas reflexões políticas, pois este amor jamais pode ser explicitado publicamente e contextualmente pelos homens senão mediante transfigurações. O que Arendt assume é que, para que não vivamos no deserto, temos de habitar e conviver no mundo com amor e gratidão pela responsabilidade que temos por ele: e isso se demonstra inclusive pela interação com os nossos pares através do respeito e da amizade, pela capacidade de se fazer promessas e compromissos mútuos e tomar decisões em comum, seja para revolucionar, inovar ou estabilizar o âmbito mundano. É à luz desse amor pelo mundo que o espírito revolucionário, do qual Arendt trata em Sobre a Revolução, pode ganhar significado a partir de dois elementos quase irreconciliáveis: por um lado, a preocupação com a estabilidade e a durabilidade do novo corpo político; e, por outro lado, a afirmação sempre revigorante do nascimento de algo novo na terra. Isto é, o ato de fundação levado a cabo pelas revoluções modernas está dependente, de modo concomitante, da anunciação da novidade e da esperança da estabilidade. Nesse contexto, o espírito revolucionário ${ }^{4}$ só pode ser aquele que se mostra capaz de conciliar tais posturas contraditórias para aquém, ou além, das divisões binárias, contemporâneas e ideológicas entre "direita e esquerda, reacionário e progressista, conservadorismo e liberalismo, para citar apenas alguns ao acaso" (Arendt, 2011, p.284). Enfim, o espírito revolucionário é também uma expressão plena do amor mundi nos termos de Arendt e, afirma a autora, o próprio legado revolucionário deu origem a um dos sintomas da perda desse espírito, que está declarada no modo como atualmente a terminologia e o funcionamento políticos solidificaram a contraposição e o completo afastamento entre esses dois tipos de atos e pensamentos: o da defesa da permanência e o da defesa da alteração via novidade. "Afinal, hoje em dia, nada compromete mais seriamente o entendimento e o debate significativo das questões políticas do que os reflexos mentais automáticos e condicionados pelas trilhas batidas das ideologias nascidas, todas elas, nas pegadas e na esteira da revolução" (idem, p.283 $)^{5}$. De uma perspectiva mais abstrata, Arendt está colocando em pauta que um mundo sem quaisquer tipos de autoridades, conservação, estabilidade, instituições permanentes, tradição e, inclusive, preconceitos, seria também completamente indissolúvel em nossas capacidades compreensivas e totalmente inóspito aos seres

4 Não é por acaso, então, que Arendt enxerga em Maquiavel o pai espiritual das revoluções modernas. Foi Maquiavel o primeiro autor a se interessar seriamente pelo dilema da fundação de um corpo político duradouro e de sua dupla perplexidade: o estabelecimento de um novo início e a necessidade de uma autoridade mantenedora.

$5 \mathrm{Em}$ um debate acadêmico realizado no Canadá, ao ser interrogada sobre como se definiria dentro das possibilidades contemporâneas do conservadorismo e do liberalismo político, Arendt responde com o mesmo desgosto sobre tais oposições: "Não sei. Realmente não sei e nunca soube. Suponho que nunca tive uma posição como essa. Você sabe que a esquerda pensa que sou conservadora e os conservadores algumas vezes pensam que sou de esquerda, uma dissidente ou Deus sabe o quê. Devo dizer que não me importo. Não penso que as verdadeiras questões deste século recebam qualquer tipo de iluminação por esse tipo de coisa" (Arendt, 2010a, p.157). 
humanos que chegam, como plenos estrangeiros, ao contexto mundano pelo milagre renovador do nascimento. Reconhecer que não meramente estamos, mas que somos inescapavelmente do mundo - e que isso implica assumir todas as suas contradições e tensões em nossos atos e espírito - é amar o único habitat, o único lar, possível aos homens.

É interessante perceber que nos seus textos de preocupações morais, posteriores ao seu contato com Adolf Eichmann, no julgamento que culminou no enforcamento deste, Arendt vai defender que na relação de si para si mesmo - uma tal relação que é realizada pelo dois-em-um característico da atividade de pensar e que vai se postar no hiato entre a consciência moral e a conduta moral de um indivíduo - o que deve prevalecer nesta relação é outro tipo de sentimento: é justamente o respeito; não é o amor a si mesmo. Não pratico o mal, diz Arendt, pois respeito a companhia que sou para mim mesmo e não gostaria de ser condenado a conviver ao lado de um malfeitor - eu mesmo. O respeito a si mesmo é um modo de resguardar a pluralidade, ou a "lei do mundo", até mesmo no processo interno mental. Assim como posso respeitar, concordar e discordar dos outros homens, é possível também entrar em concórdia ou discórdia comigo mesmo: o dois-em-um possibilita-nos uma relação plural em que trato a mim mesmo enquanto outro, orgulhando ou desprezando os meus próprios feitos. Não obstante, pode-se avançar nisso e dizer que o respeito a mim mesmo resguarda um dos aspectos mundanos dentro de mim. Caso a orientação ética, que, segundo Arendt, se funda subjetivamente pela capacidade do pensamento, fosse suplantada pelo "amor próprio", todo espaço-entre seria abolido por conta da própria característica acósmica do amor, o "eu" seria ensimesmado e sem abertura para o mundo. Enfim, é justamente porque o dois-em-um preza pela harmonia e pelo respeito, e não pelo amor, que o espaço-entre é afirmado no próprio interior do self; é este espaço que me une e que também me separa de mim mesmo, bipartindo minha identidade.

Deste modo, temos que se a preocupação política se constitui pelo amor ao mundo; a preocupação moral, por sua vez, se constitui primariamente pelo respeito a uma concordância consigo mesmo: "não é uma questão de humildade, mas de dignidade humana e até de orgulho humano. 0 padrão não é nem o amor por algum próximo, nem o amor por si próprio, mas o respeito por si mesmo" (Arendt, 2008, p.131). Todavia, pretende-se demonstrar que essas definições não implicam total contrariedade entre o político e o ético nas reflexões de Arendt, não só porque o dois-em-um do pensamento pressupõe a pluralidade humana, mas sobretudo pela afirmação da autora de que o "desprendimento de si mesmo" é o critério crucial para a escolha de um modo de conduta positivo, para além da negação de um modo de conduta aferida pelo critério do diálogo interno que tenho comigo mesmo a partir do processo do pensamento. Nesse contexto, Arendt sugere que o “desprendimento de 
si", no sentido da afirmação de outros e não de mim mesmo, traz consigo a análise das faculdades da vontade e do juízo. Assim, uma vez inserido nos temas da vida do espírito, para finalizar, este artigo pretende sugerir o caminho dos últimos dois momentos nos quais se pode relacionar a expressão "amor" à política, à revolução e à ética nas reflexões arendtianas. Um desses momentos se encontra no volume sobre "O querer", de A Vida do Espírito; e o outro momento, talvez o mais ousado aqui pretendido, se localiza em um artigo intitulado "Compreensão e Política”, de 1953.

Quando dedica uma parte de seu último livro para dialogar com Agostinho a respeito da vontade, essa faculdade humana que teria tido seu descobrimento realizado pelos medievais, Arendt alega que em todo ato da vontade há uma tensão envolvida entre um "eu-quero" e um "não-quero". Este conflito, que é permanente na vontade, segundo Arendt, só tem seu fim com a ação; ou seja, só quando o egovolitivo cessa de querer, e se põe a agir, que há redenção para esse contraste interno ao espírito. A dinâmica da faculdade da vontade não é um diálogo harmonioso e silencioso (como o é o pensamento), mas uma luta constante que precisa chegar a um fim que não se esgota no mero processo de querer. Ou seja, nenhuma vontade é cessada apenas mentalmente, é preciso que alcance algo objetivo por meio da própria ação individual que delibera por um lado [velle] ou pelo outro [nolle]. 0 importante nesse argumento é que Arendt parece concordar com Agostinho no sentido de que essa solução na ação se dá juntamente com o transformar da vontade em "amor". Assim, se se relembra que a vontade é uma espécie de "fonte da ação", o órgão mental da liberdade (cf. Arendt, 2009a, pp.359,366-7), que é por meio dela que decidimos como desejamos aparecer publicamente, que ela é o árbitro do juízo - que diz "sim” ou "não" a determinadas coisas ou a determinadas formas de conduta -, o amor, então, enquanto vontade redimida, torna-se precondição para a ação (o que é diferente de critério). Por conseguinte, torna-se também necessário à sustentação de uma ética da aparência, porque mediante a vontade, ou o amor, no caso, afirmamos não só nosso desejo da permanência do mundo, mas também nossa conduta em função da permanência das outras pessoas pelos limites intersubjetivos do bom convívio. A pedra de toque da vontade não é o próprio self, mas a responsabilidade pelos outros seres humanos e pelo próprio mundo, uma vez que a vontade sempre se redime no agir. "Não há maior afirmação de algo ou alguém do que amar este algo ou alguém, isto é, do que dizer: quero que sejas - Amo: Volo ut sis" (idem, p.268). Agir significa, a cada instante de acontecimento, um dizer "sim" por parte da vontade em relação ao mundo (mesmo podendo dizer “não”, “não entrarei em ação”) - é dizer: eu quero afirmar a liberdade e me responsabilizar pelas consequências inerentes a ela e, dessa maneira, conectar-me aos homens pela ação.

Em outras palavras, a vontade é a atividade mental correspondente à ação, em Arendt, pois é justamente a partir dos atributos dela que os homens possuem 
espontaneidade espiritual e poder de livre escolha, isto é, a vontade reafirma as capacidades da deliberação individual e da renovação por meio de um ato inicial. Tratase de uma precondição para o amor mundi em dois aspectos distintos e relacionados: político e moral. "Nesse sentido, o mundo seria dilectores mundi. Ou seja, o amor do mundo constitui o mundo para mim, [a minha vontade determina] a forma como eu me ajusto no mundo. Assim, das minhas afirmações e negações dependerá a quem e a que eu pertenço" (Arendt, 1966, p.024560). Ou seja, há sempre uma personalidade, uma singularidade, passível de caráter público, subjacente a cada ato e fala pelos quais aparecemos no mundo. A vontade, diz Arendt, sempre mira o porvir, o "ainda não", é sempre o sustentáculo da promessa humana de responder por si mesmo no amanhã. Não custa lembrar que o ato da fundação revolucionário coincide com o olhar para o futuro, com o olhar preservador, como que uma "memória da vontade" de um espírito fundante de querer manter a liberdade enquanto um fato no espaço público. Enfim, a volição é capaz de conservar o quem aparece, decidir com que forma o quem pretende aparecer e de conferir prosperidade espiritual às fundações políticas humanas.

Por fim, o último ponto abordado se refere à faculdade do juízo, que também se relaciona ao desprendimento de si mesmo, como confirma Arendt:

A eficácia do juízo repousa em uma concórdia potencial com outrem, e o processo pensante que é ativo no julgamento de algo não é, como o processo de pensamento do raciocínio puro, um diálogo de mim para comigo, porém se acha sempre e fundamentalmente, mesmo que eu esteja inteiramente só ao tomar minha decisão, em antecipada comunicação com os outros com quem sei que devo afinal chegar a algum acordo. O juízo obtém sua validade específica desse acordo potencial (...) Que a capacidade para julgar é uma faculdade especificamente política, exatamente no sentido denotado por Kant, a saber, a faculdade de ver as coisas não apenas do próprio ponto de vista mas na perspectiva de todos aqueles que porventura estejam presentes (...) a compreensão disso é virtualmente tão antiga como a experiência política articulada. Os gregos davam a essa faculdade o nome de phrónesis (Arendt, 2009, pp.274-5).

Em um dos últimos parágrafos de "Compreensão e Política”, Arendt relembra a velha prece do Rei Salomão que roga a Deus o maior dos dons que qualquer homem poderia ter, qual seja: um “coração compreensivo”. Arendt, não só confere sabedoria prática a Salomão por esse pedido, mas traduz o "coração compreensivo" como sendo a faculdade da imaginação. De fato, não haveria melhor tradução. Um "coração compreensivo", muito além do sentimentalismo (que nada tem a ver com expor em público emoções e sentimentos privados como se fossem virtudes morais), se liga diretamente à mentalidade alargada, à amplitude do espírito, ou seja, à capacidade de treinar o pensamento a sair em visita de outros pontos de vistas que não o seu, à formulação de juízos próprios sem deixar de ter em conta possíveis juízos alheios. Em resumo, sem a capacidade da imaginação não haveria o juízo reflexionante, nem 
em Kant e nem em Arendt, pois o processo de "percepção de outras perspectivas" e o abandono das próprias idiossincrasias dependem do modo funcional do poder imaginativo - de ter presente espiritualmente algo que está ausente dos sentidos, por exemplo. É ainda mais considerável que nessa passagem bíblica, I Reis, a prece de Salomão é justificada perante Deus para que haja juízo reto do rei sobre seu povo. Assim, ao fazer uma análise da expressão "coração compreensivo", sob as lentes conceituais arendtianas, é muito difícil não vincular "coração" a "amor"; e "compreensivo" à reconciliação com o mundo (reconciliação que, por acaso, em Arendt, possui uma conotação religiosa, de religar, religare - que, em seu sentido romano original, significa ligação de volta a um início, consistia em voltar a se vincular ao início da história, à fundação da cidade, à fundação de Roma). Enfim, pode-se apontar, primeiro, que só se sente em casa no mundo quem o ama, diz Arendt: "o coração humano é a única coisa no mundo que toma a si o fardo que nos é atribuído pela divina dádiva da ação” (Arendt, 1993, p.52). Pode-se afirmar também que o poder de um coração compreensivo, a rigor, é o de levar o outro em conta, de reverter perspectivas, de deliberar entre pares, do esforço consciente também dos homens da revolução de lidarem com as perplexidades do início recorrendo ao "espírito da antiga prudência", capacidades provindas do juízo humano tal qual, diz Arendt, "o curso da Revolução Americana conta uma história inesquecível e pode ensinar uma lição sem igual” (Arendt, 2011, p.273).

É exatamente a partir do aprendizado de uma lição histórica, da força educativa das exemplaridades, que o juízo humano recebe e provê a sua marca ética distintiva. Em Algumas questões de filosofia moral, Arendt comenta que os exemplos também constituem sinais de orientação para todo tipo de pensamento moral e, de certo modo, ajudam na decisão sobre o certo e o errado. "Julgamos e distinguimos o certo do errado por termos presente em nosso espírito algum incidente e alguma pessoa, ausentes no tempo e no espaço, os quais se tornaram exemplos. Há muitos desses exemplos. Podem estar no passado remoto ou entre os vivos. Não precisam ser realidade histórica” (Arendt, 2008, p.211). Ao contrário de um esquema geral, a exemplaridade nos ofereceria uma diferença qualitativa com a qual se espelhar e por meio da qual basear nossas ações de conduta. Novamente aqui a questão sobre a escolha de companhia se faz saliente: podemos escolher com quem conviver, ao pensarmos na nossa própria conduta moral, mirando em exemplos de personalidades, bem como exemplos de experiências aprendidas, ocorridas ou imaginadas. Mas é claro que esse tipo de decisão, pondera Arendt, não possui a validade das proposições cognitivas. Nunca podemos compelir alguém a concordar com esse tipo de juízo particular - isto é belo, isto é feio, isto é certo, isto é errado -, apenas podemos cortejar ou pretender o acordo de todos os demais, até porque reivindica a aprovação dos outros por tê-los levado em consideração pela própria 
mentalidade alargada e, por isso, é de se esperar que o julgamento contenha certa validade geral. Para Arendt, esta validade pode se estender a toda comunidade da qual nosso senso comum nos torna membros. É a interação com as outras pessoas que faz validar esse tipo de senso comum, que, por sua vez, vai garantir comunicabilidade aos juízos formulados na ausência de um padrão universal reconhecido por todos. É na defesa do senso comum que o amor mundi deixa de ser apenas um conceito filosófico.

\section{Referências}

Arendt, H. (1966). “Basic Moral Propositions”. In: Lectures, 1966. Chicago: University of Chicago, Hannah Arendt's Papers, The Manuscript Division, Library of Congress, container 46.

(1978). The Jew as Pariah: jewish identity and politics in the modern age. Ron H. Feldman (ed.). New York: Groove Press. Janeiro: Relume-Dumará.

(1993). A dignidade da política. Antônio Abranches (org.). Rio de . (1997). O conceito de amor em Santo Agostinho. São Paulo: Instituto Piaget.

Letras.

. (2008). Responsabilidade e julgamento. São Paulo: Companhia das Paulo: Perspectiva.

. (2009). Entre o Passado e o Futuro. Tradução de Mauro W. Barbosa. São - (2009a). A vida do espírito. Rio de Janeiro: Civilização Brasileira. - (2010). A condição humana. Tradução de Roberto Raposo (Revisão de Adriano Correia). 11. ed. Rio de Janeiro: Forense Universitária. - (2010a). Sobre Hannah Arendt. Tradução de Adriano Correia. Revista Inquietude, 1(2), pp.122-163.

. (2011). Sobre a Revolução. Tradução de Denise Bottmann. São Paulo: Companhia das letras.

Biemel, W; Saner, H. (1990). Martin Heidegger / Karl Jaspers: Correpondencia (19201963). Madri: Editorial Sintesis.

Kristeva, J. (2002). O gênio feminino: a vida, a loucura e as palavras. Rio de Janeiro: Rocco.

Nietzsche, F. (2001). Para além do bem e do mal: ou o prelúdio de uma filosofia do futuro. Curitiba: Hemus.

Young-Bruehl, E. (1984). Hannah Arendt: for love of the world. New Haven: Yale University Press. 